\title{
A comparative prospective observational study on the use of ulipristal acetate versus mifepristone in reduction of the size of uterine leiomyoma
}

\author{
Lipika Ghosh', Abhijit Rakshit' ${ }^{2}$, Madhumita De $^{3}$ \\ ${ }^{1}$ Senior Resident, Department of Obstetrics and Gynaecology, College of Medicine and Sagore Dutta Hospital, \\ ${ }^{2}$ Associate Professor, Department of Obstetrics and Gynaecology, ${ }^{3}$ Assistant Professor, Department of Physiology, \\ R. G. Kar Medical College and Hospital, Kolkata, West Bengal, India
}

Background: Fibroid or uterine leiomyoma is the most common benign tumor of the uterus in the reproductive age group and found in one out of every four women. They are symptomatic in $50 \%$ of women, with the peak incidence occurring among women in their 30 s or 40 s. Fibroid can cause a variety of symptoms which include menstrual disturbances commonly menorrhagia and dysmenorrhea. It is a common indication of hysterectomy in Indians. An effective medical treatment option may reduce hysterectomy-associated morbidity and mortality. This study is undertaken to evaluate the efficacy and safety of medical management of myoma and contribution in the reduction of myoma size comparing the two drugs ulipristal and mifepristone. Aims and Objectives: The study was conducted to compare reduction of menorrhagia (By pictorial blood loss assessment chart score), reduction of fibroid size (using transvaginal ultrasonography), and improvement of hemoglobin $(\mathrm{Hb})$ level. We are also evaluating safety or side effects using these drugs. Materials and Methods: The study includes 210 patients who are divided into two groups. Group A includes 105 patients who are treated with tablet Ulipristal Acetate $5 \mathrm{mg}$ daily for 3 months and Group B includes 105 patients who are treated with tablet mifepristone $25 \mathrm{mg}$ daily for 3 months. Results: Ulipristal and mifepristone both are effective in reduction of menorrhagia and improvement of $\mathrm{Hb}$ levels, but Ulipristal is more effective in reduction of size of uterine myoma than mifepristone after 3 months of treatment. Conclusion: Multicentric study over Access this article online

Website:

http://nepjol.info/index.php/AJMS DOI: 10.3126/ajms.v13i1.40753

E-ISSN: 2091-0576

P-ISSN: 2467-9100

Copyright (c) 2022 Asian Journal of Medical Sciences

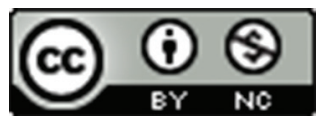

This work is licensed under a Creative Commons Attribution-NonCommercial 4.0 International License.

Key words: Leiomyoma; Mifepristone; Ulipristal acetate

\section{INTRODUCTION}

Leiomyoma (fibroid) is a common concern causing heavy menstrual bleeding, abdominal pain, pressure symptoms, subfertility, or infertility. The prevalence of uterine fibroid in India is up to $20-30 \%$ in reproductive females ${ }^{1}$ and $10-20 \%$ of infertile women are diagnosed with uterine fibroid., ${ }^{2,3}$

Over the years, hysterectomy and myomectomy had been the traditional mode of treatment for uterine fibroid. ${ }^{4}$ Although the traditional route, laparotomy has evolved into a more conservative less invasive laparoscopy, many women might not prefer surgery due to fear or the concept of disturbed fertility and of course of loosing the uterus. Even perimenopausal women not desiring uterus conservation for childbearing may not prefer hysterectomy for retaining their menstrual function related to feminity.

Growing evidences from histological, clinical, biochemical, and pharmacological studies indicate that progesterone and estrogen receptor plays a key role in the development and growth of uterine leiomyoma. ${ }^{5}$ Progesterone causes 
suppressed apoptosis and stimulates proliferation of the leiomyomatosis smooth muscles. ${ }^{6}$ Whereas estrogen indirectly stimulates leiomyoma growth by up-regulating the progesterone receptors.

Years back, combined oral contraceptive and progesteronecontaining preparation were considered to reduce heavy menstrual bleeding (HMB) associated with leiomyoma but they were not found to reduce the size of myomas.

Next drug, Danazol (in 1971), a synthetic androgen with antiprogestational and antiestrogenic activity, appeared to be a potential drug in leiomyoma management. However, gradually its use was also withdrawn due to its androgenic side effects such as acne, hirsutism, and weight gain. ${ }^{7}$

Gonadotrophin-releasing hormone $(\mathrm{GnRH})$ was introduced in late 1980. GnRH causes inhibition of the pituitary axis thereby suppressing the release of luteinizing hormone, follicle-stimulating hormone from it, and in turn estrogen and progesterone from the ovary. The use of GnRH analogs causes reduction of leiomyoma size, vascularity as well as clinical symptoms significantly. But owing to its major disadvantages such as high cost, menopausal symptoms and bone demineralization (on prolonged therapy) clinicians discouraged its widespread use in treating myomas. ${ }^{8}$

Since it has long been established that estrogen and progesterone promote leiomyoma growth, it encouraged the use of anti-progesterone/estrogen receptor modulators and aromatase inhibitors to treat them. Hence, there was surge of studies evaluating effect of anti progesteronelike mifepristone, ulipristal acetate (PEARL STUDY) as well as aromatase inhibitors with antiestrogenic action on the uterus such as Anastrozole in non-surgical treatment choices for uterine myomas.

Currently, two anti progesterones; mifepristone (progesterone receptor antagonist) and ulipristal acetate (selective progesterone receptor modulator) both are available as treatment modality of leiomyoma with equal efficacy but low cost of mifepristone is responsible for its more gaining popularity over ulipristal.

Ulipristal acetate reversibly blocks the progesterone receptors in the uterus and down regulate the expression of angiogenic growth factors, for example, vascular endothelial growth factor (VEGF), thereby causing a significant reduction in the size of leiomyoma and its vascularity. No major disadvantages associated with these group of drugs have been reported apart from its high cost, which restrict its use in every section of society for fibroid treatment.
Mifepristone (RU-486) was introduced in 1980 and came into use in 1987, which emerged as a boon for fibroid patients. It has multiprong action on leiomyoma. It binds strongly to endometrial progesterone receptor, minimally to estrogen receptor and upregulate androgen receptors, and most importantly downregulation of progesterone receptors. ${ }^{9}$ Reduction in size of myoma with mifepristone must be due to its direct effect in reduction of progesterone receptors in leiomyomatosis cells. Androgen receptors also contribute to anti-proliferative effect. ${ }^{10} \mathrm{In}$ addition, mifepristone also inhibits or delay ovulation, which may produce amenorrhea. Direct suppressive effect on endometrial vasculature as well as on reducing stromal VEGF has also been suggested for reducing menstrual blood loss. ${ }^{10}$ The betterment of mifepristone over $\mathrm{GnRH}$ analog lies in its oral administration, fewer side effects, and less expense than GnRH analog.

\section{Aims and objectives}

1. To compare the effect of mifepristone and ulipristal acetate on

- Symptomatology of fibroid

- Size and Vascularity of fibroid

2. To compare acceptability and compliance of mifepristone and ulipristal

3. To compare the adverse effects of mifepristone and ulipristal.

\section{MATERIALS AND METHODS}

The present study was conducted in the department of Obstetrics and Gynaecology at R. G. Kar Medical College and Hospital, Kolkata over a period of 1 year between 2017 and 2018. Approximately 210 women of age $20-50$ years with symptomatic and asymptomatic fibromyoma were enrolled in the study after taking valid and informed consent. Asymptomatic patients were also included in the study, as this study was conducted to elicit the response of the drug with respect to size and vascularity of fibromyoma as well. The factor affecting their decision to get enrolled was their concern about having uterine tumor even though asymptomatic.

The exclusion criteria:

1. Big Fibroid (size more than $15 \mathrm{~cm}$ by ultrasonography)

2. Uterine size $>16$ weeks

3. Coexisting adenomyosis, endometriosis, and adnexal masses Malignancies of uterus/cervix/ovary/vagina/endometrial hyperplasia with atypia (Patients with endometrial thickness more than $15 \mathrm{~mm}$ were included in the study only after ruling out cellular atypia by aspiration cytology)

- On hormonal medication within 3 months.

- Medical diseases such as liver dysfunction, heart disease, migraine, stroke, renal disease,hypo/ hyperthyroidism, platelet disorders, or coagulopathy 
Table 1: Distribution of mean age versus group

\begin{tabular}{lccccccc}
\hline Age & Number & Mean & SD & Minimum & Maximum & Median & P-value \\
\hline Group-A & 105 & 38.8095 & 7.3079 & 20.0000 & 55.0000 & 40.0000 & 0.7001 \\
Group-B & 105 & 38.3905 & 8.4004 & 20.0000 & 54.0000 & 40.0000 & \\
\hline
\end{tabular}

Table 2: Distribution of mean PBAC score pre versus group

\begin{tabular}{lccccccc}
\hline PBAC pre & Number & Mean & SD & Minimum & Maximum & Median & P-value \\
\hline Group-A & 105 & 262.8095 & 49.3561 & 120.0000 & 360.0000 & 270.0000 & 0.0003 \\
Group-B & 105 & 237.7143 & 50.1825 & 120.0000 & 340.0000 & 230.0000 & \\
\hline
\end{tabular}

PBAC: Pictorial blood loss assessment chart

Table 3: Distribution of mean PBAC score post versus group

\begin{tabular}{lccccrrr}
\hline $\begin{array}{l}\text { PBAC } \\
\text { Post }\end{array}$ & Number & Mean & SD & Minimum & Maximum & Median & \\
\hline Group-A & 105 & 153.8095 & 40.7356 & 90.0000 & 270.0000 & 150.0000 \\
Group-B & 105 & 139.2381 & 36.5441 & 65.0000 & 240.0000 & 140.0000 \\
\hline
\end{tabular}

Table 4: Distribution of mean Hb level pre versus group

\begin{tabular}{lccccccc}
\hline Hb pre & Number & Mean & SD & Minimum & Maximum & Median & P-value \\
\hline Group-A & 105 & 8.3895 & 0.8248 & 6.7000 & 10.2000 & 8.2000 & 0.0001 \\
Group-B & 105 & 8.7752 & 0.5181 & 7.9000 & 10.0000 & 8.9000 & \\
\hline
\end{tabular}

$\mathrm{Hb}$ : Haemoglobin

Table 5: Distribution of mean $\mathrm{Hb}$ level post versus group

\begin{tabular}{cccccccc}
\hline Hb post & Number & Mean & SD & Minimum & Maximum & Median & P-value \\
\hline Group-A & 105 & 9.7067 & 0.7955 & 7.0000 & 12.0000 & 9.8000 & 0.1278 \\
Group-B & 105 & 9.8562 & 0.6094 & 8.1000 & 11.5000 & 9.9000 & \\
\hline
\end{tabular}

$\mathrm{Hb}$ : Haemoglobin

Table 6: Distribution of mean fibroid size pretreatment versus group

\begin{tabular}{|c|c|c|c|c|c|c|c|}
\hline Fibroid size pre & Number & Mean & SD & Minimum & Maximum & Median & P-value \\
\hline Group-A & 105 & 5.6097 & 1.1933 & 3.0000 & 9.0000 & 5.7000 & $<0.001$ \\
\hline Group-B & 105 & 4.4848 & 0.8998 & 3.0000 & 7.1000 & 4.4000 & \\
\hline
\end{tabular}

\section{Table 7: Distribution of mean fibroid size post versus group}

\begin{tabular}{|c|c|c|c|c|c|c|c|}
\hline Fibroid size post & Number & Mean & SD & Minimum & Maximum & Median & P-value \\
\hline Group-A & 105 & 4.0164 & 1.0891 & 1.5000 & 6.3000 & 4.0000 & 0.0006 \\
\hline Group-B & 104 & 3.5356 & 0.8983 & 1.5000 & 6.0000 & 3.5000 & \\
\hline
\end{tabular}

- Hypersensitivity to the drug

- Very severe anemia $<6 \mathrm{~g} / \mathrm{dl}$

4. Detailed history of the patients enrolled for the study, was taken. Thorough general, systemic and gynecological examination was done at first visit and then after 3 months and 6 months of therapy.

5. All 210 patients were subjected to complete blood count, serum thyroid-stimulating hormone, liver function test, renal function test, HIV, HBsAg.

6. All the patients with HMB and hemoglobin $(\mathrm{Hb})$ level $<10 \mathrm{~g} / \mathrm{dl}$ were counseled to take iron and other micronutrient rich diet and were given iron sulfate $60 \mathrm{mg}$ that was available in our government supply for a period of 6 months and follow up of $\mathrm{Hb}$ level was done at 3 and 6 months.

Methods applied for various assessment

Menstrual blood loss assessment

Pictorial blood loss assessment chart (PBAC) 
In this study, objective assessment of menstrual blood loss was done by PBAC as devised by Halimeh et al. ${ }^{11}$ $\mathrm{PBAC}$ is a simple and less time-consuming procedure for objective assessment of menstrual blood loss. Using the scales as described below, the total score is calculated by adding up the sum of all scores for the sanitary napkin used in the menstrual cycle. The patients were asked to use certain sanitary napkins which had similar absorbent capacities and were advised to maintain a menstrual diary to record the total number of days of bleeding, number of sanitary pads used, degree of soaking of each pad, number and size of clots passed. Number of sanitary pads used each day ( $24 \mathrm{~h}$ period) were counted. A score for each day was calculated and then the score was added up at the end of the month. Scoring of soaked sanitary napkins was: 1 score for lightly stained, 5 scores for moderately soiled, and 20 scores for completely saturated pads. Clots were given a score of 1 for small and 5 for large clots. Possible range of total score was completely dependent on quantitative and qualitative amount of bleeding during menstruation. Abnormal PBAC score $\geq 100$, which correlates with menorrhagia, is defined as $>80 \mathrm{~mL}$ of menstrual blood loss.

\section{Assessment of fibroid size, number, endometrial thickness}

It was measured preferably by high-resolution ultrasonography machine with Doppler velocimetry. The transvaginal approach was preferred with a $5 \mathrm{MHz}$ probe (for $\mathrm{B}$ mode imaging) and a $6 \mathrm{MHz}$ probe (for color flow imaging). Even those patients who were prediagnosed with uterine leiomyoma evidenced by transabdominal ultrasound (USG), were also included in the study. In USG the uterus was examined systematically and fibroids were recorded only if their maximum diameter was atleast $0.5 \mathrm{~cm}$ and could be visualized in all the three planes. Each individual fibroid was measured in sagittal, longitudinal, and transverse diameter and the maximum diameter among three was choosen as size of the fibroid. Total number of fibroids calculated in each patient and the fibroid which had maximum diameter was chosen for follow-up to see the effect of treatment on their size. Endometrial thickness was measured in the longitudinal axis, at the thickest point between the two basal layers on the anterior and posterior uterine walls.

\section{Follow up}

Follow-up was done at 3 monthly and 6 monthly intervals. Side effects were assessed in terms of Gastrointestinal symptoms, abdominal pain, headache, amenorrhea, and infrequent menses.

\section{Statistical analysis}

For statistical analysis data were entered into a Microsoft Excel spreadsheet and then analyzed by Statistical Package for the Social Sciences (SPSS) (version 24.0; SPSS Inc., Chicago, IL, USA) and GraphPad Prism version 5. Data have been summarized as mean and standard deviation for numerical variables and count and percentages for categorical variables. Two-sample t-tests for a difference in mean involved independent samples or unpaired samples. Paired t-tests were a form of blocking and had greater power than unpaired tests. A Chi-square test $\left(\chi^{2}\right.$ test) was any statistical hypothesis test wherein the sampling distribution of the test statistic is a Chi-square distribution when the null hypothesis is true. Without other qualification, "Chi-square test" often is used as short for Pearson's Chi-square test. Unpaired proportions were compared by Chi-square test or Fischer's exact test, as appropriate.

Once a t-value is determined, a P-value can be found using a table of values from Student's t-distribution. $\mathrm{P} \leq 0.05$ was considered for statistically significant.

\section{RESULTS}

All 210 enrolled patients were explained about the mechanism of action, associated side effects, and cost of both the drugs. Depending on their choice the enrolled patients were divided into two groups with 105 patients in each group.

1. Group A - All fibroid patients were given ulipristal acetate $5 \mathrm{mg}$ once daily for 3 months

2. Group B - All fibroid patients were given tab mifepristone $25 \mathrm{mg}$ daily for 3 months followed by $60 \mathrm{mg}$ once weekly for another 3 months.

Table 1 showed in group- $\mathrm{A}$, the mean age (mean \pm s.d.) of patients was $38.8095 \pm 7.3079$ years. In group-B, the mean age (mean \pm s.d.) of patients was $38.3905 \pm 8.4004$ years. It was not statistically significant $(\mathrm{p}=0.7001)$.

Table 2 showed in group-A, the mean PBAC score of Pretreatment (PBAC Pre) (mean \pm S.D.) of patients was 262.8095 \pm 49.3561 . In group $B$, the mean PBAC Pre (mean \pm S.D.) of patients was 237.7143 \pm 50.1825 . Distribution of mean PBAC of Pre-treatment versus group was statistically significant $(\mathrm{P}=0.0003)$.

Table 3 revealed that in group- $A$, the mean PBAC score of Post-treatment (PBAC post) (mean \pm S.D.) of patients was $153.8095 \pm 40.7356$. In group $B$, the mean PBAC post (mean \pm S.D.) of patients was $139.2381 \pm 36.5441$. 
Distribution of mean PBAC post versus group was statistically significant $(\mathrm{P}=0.0069)$.

Table 4 depicted that in group- $\mathrm{A}$, the mean $\mathrm{Hb}$ pretreatment (mean \pm S.D.) of patients was $8.3895 \pm 0.8248$. In group B, the mean $\mathrm{Hb}$ pretreatment (mean \pm S.D.) of patients was $8.7752 \pm 0.5181$. Distribution of mean HB pretreatment versus group was statistically significant $(\mathrm{P}=0.0001)$.

Table 5 showed in group- $\mathrm{A}$, the mean $\mathrm{Hb}$ post-treatment (Hb post) (mean \pm S.D.) of patients was $9.7067 \pm 0.7955$. In group $\mathrm{B}$, the mean $\mathrm{Hb}$ post (mean \pm S.D.) of patients was 9.8562 \pm 0.6094 . Distribution of mean $\mathrm{Hb}$ post versus group was not statistically significant $(\mathrm{P}=0.1278)$.

Table 6 revealed in group-A, the mean Fibroid size pretreatment (mean \pm S.D.) of patients was $5.6097 \pm 1.1933$. In group B, the mean FS PRE (mean \pm S.D.) of patients was 4.4848 \pm 0.8998 . Distribution of mean FS pre versus group was statistically significant $(\mathrm{P}<0.001)$.

Table 7 depicted in group- $A$, the mean Fibroid size posttreatment (mean \pm S.D.) of patients was $4.0164 \pm 1.0891$. In group B, the mean Fibroid size posttreatment (mean \pm S.D.) of patients was $3.5356 \pm 0.8983$. Distribution of mean Fibroid size posttreatment versus group was statistically significant $(\mathrm{P}=0.0006)$.

\section{DISCUSSION}

Maximum number of patients (34.4\%) in total study population belonged to the age group between 41 and 45 years, while the minimum number of patients $(10.3 \%)$ belonged to the age group between 20 and 25 years. The textbooks say that the maximum age incidence for leiomyoma uterus is in the reproductive age group ${ }^{12}$ but in our study maximum age incidence was between 41 and 45 years. The fact can be explained on the basis of the Indian scenario where females tend to seek treatment only when symptoms become severe enough to disable them to perform their routine activities and they are enough capable to motivate their guardians to bring them to the hospital. Moreover, at earlier ages, these fibroids might be small with no symptoms or only minimal symptoms that could have been tolerated by these women. Their high tolerance develops the tendency to ignore the complaints and consult clinician comparatively late. Additionally, with advancing age, size of these fibroid increase producing more severe symptoms leading to forcible visit to the hospital.

Amongst all patients, the most common complaint was HMB without dysmenorrhoea followed by HMB with dysmenorrhoea. The second most common symptom found was dyspareunia, whereas very few patients had pressure symptoms in the form of urinary and bowel complaints. Four asymptomatic patients were also enrolled in the study who were accidentally diagnosed with uterine fibroid in abdominal ultrasonography done for some other reason. Though they were asymptomatic, their inclusion was done with the purpose of demonstrating the effects of the drug in shrinking the fibroids. Various studies done showing distribution of symptomatology in fibroid patients which can be correlated with our study are, an Indian study by Dasgupta $\mathrm{M}$ et $\mathrm{al}^{13}$ and CO Ezeama et $\mathrm{al}^{14}$ who conducted a study in Nigeria and also showed maximum number of fibroid patients had menorrhagia(41\%)followed by infertility $(30 \%)$, dysmenorrhea(15.5\%) and urinary complaints $(8.7 \%)$. Khyade RL et a $1^{15}$ conducted a study (2017) in Mumbai and had shown menorrhagia (78\%) followed by dysmenorrhea $(30 \%)$, pain in the abdomen $(22 \%)$, frequency of micturition $(6 \%)$, infertility (4\%). So if we observe the distribution of different symptomatology in women with fibroid of the same origin, we can better correlate with the findings of Khyade et al. ${ }^{15}$ as it was again an Indian study.

On statistical comparisons, the variables of $\mathrm{HMB}$ and dysmenorrhea within both the groups showed significantly positive effects. This interprets that both the drugs are equally and highly effective in relieving the symptoms with no significant difference on comparing them. On assessing the effects of both the drugs in patients with pressure symptoms, no reductions were demonstrated. The results of our study were similar to many other studies. In the year 2012, Carbonell et al., ${ }^{12}$ conducted a study which showed a 90\% reduction in HMB, 50\% reduction in dysmenorrhea, and pain symptoms in fibroid patients taking mifepristone.

Reductions in PBAC were significant in both the groups at 3 months follow-up (group $\mathrm{A}-\mathrm{P}<0.0001$ and group $B-P<0.0001)$. Various other studies depicting similar results with ulipristal acetate were conducted by Donnez $\mathrm{J}$ et $\mathrm{al}^{3}$ two groups comprising $62 \%$ and $73 \%$ patients using $5 \mathrm{mg}$ and $10 \mathrm{mg}$ ulipristal acetate respectively, rates of amenorrhoea after each individual treatment course were higher for patient receiving $10 \mathrm{mg}(83 \%)$ than $5 \mathrm{mg}$ $(72-74 \%)$ and size of uterine fibroid reduced to $36 \%$ in group using $5 \mathrm{mg}$ ulipristal daily and $42 \%$ in group using tab ulipristal $10 \mathrm{mg}$ daily. Similar effects were seen in studies done on mifepristone also, Kulshrestha et al., ${ }^{16}$ conducted a study in New Delhi which described a significant reduction in PBAC score $(\mathrm{P}<0.001)$ after 6 months of treatment with mifepristone and Carbonell et al., ${ }^{12}$ conducted a study in Spain, which also correlate with our study showing significant reduction in menorrhagia with mifepristone $(\mathrm{P}<0.01)$. 
All the patients with HMB and $\mathrm{Hb}$ level $<10 \mathrm{~g} / \mathrm{dl}$ were counseled to take iron and other micronutrient rich diet and were given iron sulfate $60 \mathrm{mg}$ that was available in our government supply for a period of 6 months and follow up of their $\mathrm{Hb}$ level was done at 3 and 6 months. Significant rise in $\mathrm{Hb}$ level was observed in both the group at 3 months. As both the drugs caused significant reduction in menstrual blood loss so improved $\mathrm{Hb}$ status was achieved on improving the diet and administering oral iron tablets. Both the drugs were found to increase the $\mathrm{Hb}$ level with same effectiveness that can also be correlated with the reduction of menstrual blood loss by both the drugs with similar efficacy.

Study conducted by Donnez et al. ${ }^{3}$ showed rate of amenorrhea using $5 \mathrm{mg}$ and $10 \mathrm{mg}$ uliprital acetate were $83 \%$ and $72 \%$, respectively. Proportions of patients achieving controlled bleeding during two treatment courses were $>80 \%$. Various other studies done in India and even outside showedrise in $\mathrm{Hb}$ level with mifepristone such as Mukherjee et al. ${ }^{17}$ and Hangarga et al..$^{18}$ found significant rise in $\mathrm{Hb}$ level with mifepristone use in fibroid patients.

It is depicted in our study, that ulipristal caused significant reduction in size of fibroid whereas mifepristone caused only insignificant reduction in size of fibroid. With mifepristone, the study results were similar to our study, Kulshrestha et al., ${ }^{16}$ conducted a study and found $35.7 \%$ of decrease in fibroid size and Carbonell et al., ${ }^{12}$ conducted a study which showed $48.1 \%$ and $39.1 \%$ reduction in size of fibroid with use of $5 \mathrm{mg}$ and $10 \mathrm{mg}$ mifepristone, respectively.

There were no major side effects observed with any of the drugs (ulipristal and mifepristone). Maximum number of patients in both group A and group B experienced infrequent menses or amenorrhea. Besides this few patients experience nausea, emesis, pain abdomen, and headache in both groups.

\section{Limitations of the study}

The study is done among few number of people with a short time period. The cost of Ulipristal acetate is another disadvantage for the study and results loss of follow-up. We report results for only two treatment courses, but further intermittent treatment courses have been reported as effective.

\section{CONCLUSION}

The most common age group affected by fibroid was found to be $41-45$ years reflecting the Indian scenario where females seek medical advice at advanced stage of disease. Both the drugs ulipristal acetate and mifepristone found to be equally efficacious in reducing heavy menstrual bleeding, dysmenorrhea, and dyspareunia but pressure symptoms do not show significant improvement with any of these drugs. Both ulipristal and mifepristone caused significant reduction in PBAC score (ulipristal, $\mathrm{P}<0.0001$ and mifepristone, $\mathrm{P}<0.005$ ) with equal efficacy after 3 months of treatment. Both the drugs found to be equally efficacious in raising $\mathrm{Hb}$ level. Ulipristal caused reduction in the size of fibroid more effectively than mifepristone during 3 months of treatment. So, both are effective in reducing the size of fibroid. No major side effects were found to be associated with ulipristal and mifepristone except amenorrhea or infrequent menses.

\section{ACKNOWLEDGMENT}

We are grateful to the Head of our department and Radiology department of our hospital.

\section{REFERENCES}

1. Kumar P and Malhotra N. Jeffcoate's Principles of Gynecology. $7^{\text {th }}$ ed. New Delhi: Jaypee Publishing; 2008.

2. Cook H, Ezzati M, Segars JH and McCarthy K. The impact of uterine leiomyomas on reproductive outcomes. Minerva Ginecol. 2010;62(3):225-236.

3. Donnez $J$ and Jadoul P. What are the implications of myomas on fertility? A need for a debate? Hum Reprod. 2002;17(6):1424-1430.

https://doi.org/10.1093/humrep/17.6.1424

4. Ciarmela $P$, Ciavattni A, Criannubilo SR, Lamanna $P$, Fiorini R, Tranquilli AL, et al. Management of leiomyomas in perimenopausal women. Maurituis. 2014;78(3):168-173.

https://doi.org/10.1016/j.maturitas.2014.04.011

5. Cermik D and Arici A and Taylor HS. Coordinated regulation of HOX gene expression in myometrium and uterine leiomyoma. Fertil Steril. 2002;78(5):979-984.

https://doi.org/10.1016/s0015-0282(02)03366-6

6. MaruoT, Matsuo H, Shimomura Y, Kurachi O, Gao Z, Nakago S, et al. Effects of progesterone on growth factor expression in human uterine leiomyoma. Steroids. 2003;68(10-13):817-824. https://doi.org/10.1016/j.steroids.2003.08.017

7. Zotter Z, Veszeli N, Csuka D, Varga L and Farkas H. Frequency of the virilising effects of attenuated androgens reported by women with hereditary angioedema. Orphanet J Rare Dis. 2014;9:205.

https://doi.org/10.1186/s13023-014-0205-6

8. Crosignai $P G$, Vercellini $P$ and Cambridge UK. Meschea M, Oldani S and Bramante T. GnRH agonists before surgery for uterus biomyomas. A review. J Reprod Med. 1996;41(6):415-421.

9. Narvekar N, Critchley HO, Cheng L and Baird DT. Mifepristoneinduced amenorrhoea is associated with an increase in microvessel density and glucocorticoid receptor and a decrease in stromal vascular endothelial growth factor. Hum Reprod. 2006;21(9):2312-2318.

https://doi.org/10.1093/humrep/del182

10. Spitz IM. Mifepristone: Where do we come from and where are we going? Clinical development over a quarter of a century. Contraception. 2010;82(5):442-452. 
https://doi.org/10.1016/j.contraception.2009.12.012

11. Halimeh S, Rott H and Kappert G. PBAC score: An easy-to-use tool to predict coagulation disorders in women with idiopathic heavy menstrual bleeding. Haemophilia. 2016;22(3):e217-e220. https://doi.org/10.1111/hae.12886

12. Carbonell JL, Riverón AM, Cano M, Ortiz AI, Valle A, Texidó CS, et al. Mifepristone 2. $5 \mathrm{mg}$ versus $5 \mathrm{mg}$ daily in the treatment of leiomyoma before surgery. Randomized clinical trial. Int $\mathrm{J}$ Womens Health. 2012;4:75-84. https://doi.org/10.2147/IJWH.S28103

13. Dasgupta M, Karlo B, Biswas R, Bag T and Dutta S. Evaluation of the SERM ormeloxifene in the treatment of uterine fibroid in the reproductive age group. J Syndr. 2016;3(1):5. https://doi.org/10.13188/2380-6036.1000011

14. Kulshrestha V, Kriplani A, Agarwal N, Sareen N, Garg P, Hari S, et al. Low dose mifepristone in medical management of uterine leiomyoma-an experience from a tertiary care hospital from
North India. Indian J Med Res. 2013;137(6):1154-1162.

15. Ezeama CO, Ikechebelu JI, Obiechina NJ and Ezeama NN. Clinical presentation of uterine fibroids in Nnewi, Nigeria: A 5-year review. Ann Med Health Sci Res. 2012;2(2):114-118. https://doi.org/10.4103/2141-9248.105656

16. Khyade RL. A study of menstrual disturbance in cases of fibroid uterus. Int J Reprod Contracept Obstet Gynecol. 2017;6(6):2494-2497. https://doi.org/10.18203/2320-1770.ijrcog20172338

17. Mukherjee $S$ and Chakraborty S. A study evaluating the effect of mifepristone (RU-486) for the treatment of leiomyomata uteri. Niger Med J. 2011;52(3):150-152. https://doi.org/10.4103/0300-1652.86123

18. Hangarga US and Rita D. Low dose mifepristone in the treatment of uterine leiomyoma. Int J Reprod Contracept Obstet Gynecol. 2017;6(1):44-48

https://doi.org/10.18203/2320-1770.ijrcog20164498

\section{Authors Contribution:}

LG- Statistical analysis, interpreted the results, reviewed the literature, prepared first draft of manuscript; AR- Concept and design of the study, coordination, manuscript preparation; MD- Preparation of final manuscript and revision of the manuscript.

Work attributed to:

R. G. Kar Medical College and and Hospital, 1, Khudiram Bose Sarani, Kolkata-700004, West Bengal, India.

Orcid ID:

Dr. Abhijit Rakshit - (1) https://orcid.org/0000-0003-4403-7254

Source of Funding: None, Conflicts of Interest: None. 